no-take zone. Coral reef wildernesses in the Caribbean Sea and Pacific Ocean were similarly heavy with biomass. Bioscience http://dx.doi. org/10.1525/bio.2013.63.5.13 (2013)

\section{PALAEONTOLOGY \\ Winged raptor dined on fish}

A fossil of a dinosaur that was thought to feed on tree-living animals has been found with a fish in its belly.

Used to understand the origins of flight, fossils of the four-winged feathered raptor Microraptor gui, which lived 120 million years ago have previously been found with a bird and a potentially treeclimbing mammal preserved in their guts.

Scott Persons at the University of Alberta in Edmonton, Canada, and his colleagues report on a fossil (pictured) containing a partially digested fish. The authors also describe adaptations - such as front teeth that project forward that are similar to those seen in fish-hunting animals.

The feeding habits of Microraptor spp are now the best sampled of any non-avian dinosaur, revealing it as a generalist predator in arboreal and aquatic habitats, the authors say.

Evolution http://dx.doi. org/10.1111/evo.12119 (2013)

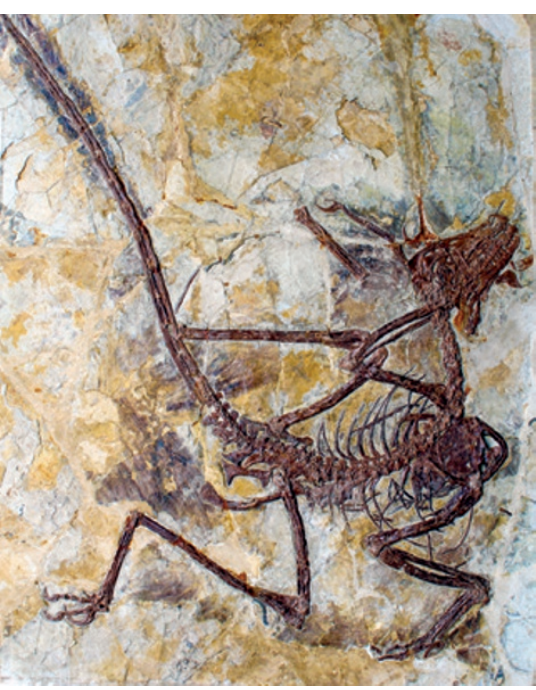

QUANTUM MECHANICS

\section{Exchange-free communication}

Researchers have proposed a mode of quantum communication whereby information could travel between two parties without the exchange of physical particles.

Quantum communication holds the promise of ultrasecure encryption, but most schemes proposed so far require the communicating parties to exchange particles. Hatim Salih at King Abdulaziz City for Science and Technology in Riyadh, Saudi Arabia, and his colleagues suggest a scheme in which a photon kept by one party is influenced by the other party opening or closing a channel between them. In principle, this allows for a measurement that can securely convey information without transferring or exchanging physical particles.

This challenges longstanding assumptions of the requirements for communication, the authors say.

Phys. Rev. Lett. 110, 170502 (2013)

\section{NEUROSCIENCE \\ Secrets of brain building revealed}

Separate studies reveal the mechanisms by which brain cells assume their rightful places.

Magdalena Götz at the

University of Munich in

Germany and her colleagues manipulated a single DNAassociated protein to promote folding in a normally smooth region of mouse brain. Low levels of the protein cause cells to divide along one plane, and high levels cause division along another. Regulation of the protein, in turn, permits complex folding that creates more room for the cerebral cortex, the layer of neural tissue covering the cerebrum. Meanwhile, researchers led by Dwight Bergles at

COMMUNITY CHOICE

The most viewed papers in science

\title{
GENOMICS
}

\section{Reading tangled RNA sequences}

\section{HIGHLY READ \\ on genomebiology. com in April}

RNA transcripts can be sequenced from biological samples, but making sense of those that fail to map exactly to a reference genome is tough. Eric Rivals at the

University of Montpellier, France, and his team have written a program called CRAC that can identify tricky transcripts as experimental errors, chromosome rearrangements, small mutations or modifications to messenger RNA. The software simultaneously matches discrete portions of sequenced RNA to locations in the genome and counts up how often unique portions are sequenced - a strategy that combines several computational steps. Although CRAC requires more memory than some similar software, it is more sensitive and precise than other tools for classifying RNA transcripts, the authors say. Genome Biol. 14, R30 (2013)

Johns Hopkins Universit
School of Medicine
in Baltimore,
Maryland, showed
how precursor cells maintain

a constant density of neural support cells as these cells differentiate and die. The team used time-lapse imaging of adult mouse brains to reveal that the mobile precursor cells constantly survey their environments and avoid each other, establishing a grid-like distribution throughout the nervous system.

Cell 153, 535-549; Nature Neur. http://dx.doi.org/10.1038/ nn3390 (2013)

\section{DEVELOPMENT}

\section{Cell signals speckle feathers}

A bird's patterned plumage is 'painted' by cell interactions.

Cheng-Ming Chuong at the University of Southern California in Los Angeles and his colleagues found that precursors of pigmentproducing cells are positioned in a ring around the base of feather follicles. These precursors divide and develop into pigment-producing cells, which are sent into the feather shaft that emerges from the follicle as feathers grow. Variations in the timing of cell development and positioning of the progenitor cells create distinct designs. Stripes are painted when pigmented cells form in synchronized pulses, and spotted feathers (pictured) result from signals that switch pigment synthesis on and off in adjacent, differentiating cells. These subtle modulations allow complex feather patterns to arise during birds' lives and to evolve over time.

Science http://dx.doi. org/10.1126/science.1230374 (2013)

\section{CORRECTION \\ In the Research Highlight 'Mechanics behind sea \\ shell spines' (Nature 496, 9; 2013), the pictured shell belonged to the Strombidae, not Muricidae, family.}

\section{$\rightarrow$ NATURE.COM}

For the latest research published by Naturevisit:

www.nature.com/latestresearch 